\title{
Neurovascular, muscle, and skin changes on [18F]FDG PET/MRI in foot complex regional pain syndrome (CRPS)
}

\section{Daehyun Yoon}

Stanford University School of Medicine https://orcid.org/0000-0001-9367-9152

\section{Yingding $\mathrm{Xu}$}

Newport Harbor Radiology Associates

Peter W. Cipriano

Stanford University School of Medicine

Israt S. Alam

Stanford University School of Medicine

\section{Carina Mari Aparici}

Stanford University School of Medicine

\section{Vivianne L. Tawfik}

Stanford University School of Medicine

\section{Catherine M. Curtin}

Stanford University School of Medicine

\section{lan R. Carroll}

Stanford University School of Medicine

Sandip Biswal ( $\square$ biswals@stanford.edu )

Stanford University School of Medicine

\section{Short communication}

Keywords: Complex regional pain syndrome, [18F]FDG PET/MRI, muscle, nerve, skin

Posted Date: October 30th, 2020

DOl: https://doi.org/10.21203/rs.3.rs-35591/v2

License: (c) (i) This work is licensed under a Creative Commons Attribution 4.0 International License. Read Full License 


\section{Abstract}

Background: The goal of this study is to demonstrate the feasibility of [18F]fluorodeoxyglucose (FDG) positron emission tomography (PET)/magnetic resonance imaging (MRI) for non-invasive visualization of muscular, neurovascular, and skin changes secondary to complex regional pain syndrome (CRPS).

Methods: Seven adult patients with CRPS in the lower extremity and seven healthy adult controls participated in our [18F]FDG PET/MRI study. All participants received whole-body PET/MRI scans one hour after the injection of $10 \mathrm{mCi}$ [18F]FDG. Resulting PET/MRI images were reviewed by two radiologists. Metabolic and anatomic abnormalities identified, were grouped into muscular, neurovascular, and skin lesions. The [18F]FDG uptake of each lesion was compared with that of corresponding areas in controls using a Mann-Whitney U-test.

Results: On PET images, muscular, neurovascular, and skin abnormalities were found in 5, 4 and 2 patients, respectively. However, on MRI images, no muscular abnormalities were detected. Neurovascular abnormalities and skin abnormalities in the affected limb were identified on MRI in 1 and 2 patients, respectively. The difference in [18F]FDG uptake between the patients and the controls was significant in muscle $(p=0.018)$ and neurovascular bundle $(p=0.0005)$.

Conclusions: The increased uptake of [18F]FDG in the symptomatic areas likely reflects the increased metabolism due to the inflammatory response causing pain. Therefore, our approach combining metabolic ([18F]FDG PET) and anatomic (MRI) imaging may offer non-invasive monitoring of the distribution and progression of inflammatory changes associated with CRPS.

Trial registration: ClinicalTrials.gov, NCT03195270. Registered 19 June 2017 - Retrospectively registered, https://clinicaltrials.gov/ct2/show/NCT03195270

\section{Introduction}

Complex regional pain syndrome (CRPS) is a severe pain condition of extremities, presenting a variety of symptoms that significantly exceeds the expected clinical progression of the injury [1]. Depending on the type of the inciting injury, it is classified into two types: CRPS I if its onset has no association with a nerve injury, and CRPS II if it is caused by a confirmed nerve injury. Due to the complexity of symptoms and disease progression, it has been very challenging to identify the exact source of pain and design effective treatments for patients with CRPS [2].

A few diagnostic approaches have been adopted to aid the diagnosis of CRPS. Plain film X-ray and three phase bone scan have been used for identifying bone loss or resorption by CRPS. However, these changes may appear temporarily and only at specific stages of CRPS [3, 4]. Magnetic resonance imaging (MRI) facilitated examining pathologic changes in musculoskeletal tissues [5], but its effectiveness has not been fully established yet [3]. Therefore, there is a pressing clinical need for improved localization of 
the CRPS-induced changes to better understand the disease mechanism and help monitor treatment effects.

In this communication, we introduce a novel imaging approach focusing on the detection of the inflammatory changes due to CRPS. Inflammation without infection is one of the key features of CRPS recognized more than 100 years ago [6]. Positron emission tomography (PET) imaging with [18F]fluorodeoxyglucose (FDG) has been frequently utilized for non-invasive localization of inflamed tissues in many diseases. The simultaneous acquisition of high-resolution MRI can facilitate the accurate specification of lesions presenting abnormally high tracer uptake on PET [7]. We performed a prospective [18F]FDG PET/MRI comparison study on CRPS patients and healthy controls to evaluate its feasibility for non-invasive detection of CRPS-induced changes.

\section{Methods}

\section{Patient population}

Seven patients who were diagnosed with CRPS in the lower extremity on the basis of symptoms and signs concordant with the Budapest criteria [8] were enrolled in our study. The diagnosis was made by pain physicians (VT, IC) and plastic surgeon (CM) at the clinical sites of our institution. The initial evaluation results of the patients are summarized in Table 1. It should be noted that all patients had received standard-of-care diagnostic exams and treatments prior to our study but failed to have satisfactory outcome. All patients were female, and the mean \pm standard deviation / range of their age was $38.7 \pm 12.4 y / 20-54 y$. Seven healthy controls were recruited to compare the [18F]FDG uptake (4 males and 3 females; $30.0 \pm 4.1 y ; 22-37 y)$.

\section{PET/MR Imaging}

The blood glucose level of subjects was maintained under $10 \mathrm{mmol} / \mathrm{L}$ by fasting for at least four hours prior to the imaging session. Any physical exercise for 24 hours prior to imaging was prohibited to suppress the unrelated metabolic activities. The use of anxiolytics was permitted, if necessary, to help subjects remain settled during the scan. A single $370 \mathrm{MBq}$ dose of [18F]FDG was administered intravenously to the subject one hour before imaging. During the whole preparation period, the subject was seated to take a rest and avoid muscle activities. All scans were conducted in a GE PET/MRI scanner (SIGNA PET/MR, General Electric Healthcare, Waukesha, WI, USA). Simultaneous PET and MRI scans covering the whole body in 8 to 10 stations were performed depending on the height of the patient. Two anterior body array coils were placed on the subject for MRI signal reception and immobilization of the subject. A fast T1-weighted scan with two-point Dixon was acquired at each station to conduct attenuation correction for PET images. The derivation of attenuation coefficient maps from the MRI images and attenuation correction were automatically handled during the scan by the algorithm offered by the vendor of the scanner $[9,10]$.

\section{Image review}


A radiologic review of [18F]FDG PET and MRI images were performed by two board-certified radiologists. The [18F]FDG PET image review aimed to detect lesions of focally increased high uptake in the affected extremities compared to the uptake of the local background and corresponding areas of healthy controls. MRI images were reviewed to identify lesions presenting either abnormally increased signal on the T2weighted contrast or showing abnormal structural changes.

\section{Statistical analysis}

Abnormalities detected on PET and MRI were classified into three tissue categories: muscle, neurovascular bundle, and skin/subcutaneous tissue. For each lesion on the PET images, a circular ROI fitting the lesion was manually drawn to measure the maximum standardized uptake value $\left(S U V_{\text {max }}\right)$. For each tissue type, the SUV $V_{\max }$ of the lesions was compared with the SUV $V_{\max }$ of healthy controls. The sample size of 7 for each group provides $80 \%$ power to detect a difference as small as 1.5 standard deviation with two-sided $5 \%$ error. Mann-Whitney U-test was employed for comparison with the p-value of 0.05 adopted as a significance level. The mean and the standard deviation of SUV $\mathrm{max}_{\text {ax }}$ of the patients and the healthy controls was also calculated for individual tissue groups.

\section{Results}

\section{PET/MRI image review}

Abnormalities were found at the reported site of pain in all seven patients on [18F]FDG PET, but in only three patients on MRI (Table 2). Increased uptake on foot muscles was the most frequent finding on PET (five patients), while, on MRI, skin thickening and nerve abnormalities were the most frequent observation (two patients, respectively). Figure 1 shows focally increased [18F]FDG uptake on the left extensor digitorum brevis muscle (1A, 1B) from a patient with left dorsal foot pain and on the left flexor digitorum brevis muscle (1C, 1D) from a patient with left plantar foot pain. Locally and globally increased [18F]FDG uptake on neurovascular bundles are respectively presented in Figure 2 and 3 . The right tibial neurovascular bundle passing through the scar tissue at the ankle showed high [18F]FDG uptake from a patient with right foot pain (2A, 2B). Figure 3 compares [18F]FDG PET images from a representative control (3A) and a patient with bilateral foot and leg pain presenting significantly high [18F]FDG uptake bilaterally on femoral, popliteal, and tibial neurovascular bundles (3B). Figure 4 displays a case of skin and subcutaneous tissue abnormalities on both [18F]FDG PET and MRI from a patient with right foot and lower leg pain.

\section{[18F]FDG uptake comparison}

Detected lesions of CRPS patients showed significantly higher [18F]FDG uptake than the corresponding regions in healthy controls (Figure 5). The mean \pm standard deviation of SUV $\mathrm{max}_{\text {ax }}$ between the detected lesions from CRPS patients and corresponding tissues from healthy controls were $1.29 \pm 0.29$ vs $0.86 \pm$ 0.19 (muscle), $1.38 \pm 0.57$ vs $0.73 \pm 0.10$ (neurovascular bundle), and $3.10 \pm 2.97$ vs $0.44 \pm 0.08$ 
(skin/subcutaneous tissues). The p-values from the SUV $\mathrm{max}_{\max }$ comparison in muscular and neurovascular tissues were 0.018 and 0.0005 , respectively, indicating a significant difference between patients and healthy controls. The p-value for the skin/subcutaneous tissue comparison could not be computed due to a limited sample size. For reference, the mean \pm standard deviation of $S U V_{\max }$ from healthy controls were $2.45 \pm 0.16$ in liver and $1.53 \pm 0.03$ in blood pool within the left ventricle while those from patients were $3.90 \pm 0.95$ in liver and $3.26 \pm 0.91$ in blood pool within the left ventricle.

\section{Discussion}

In this study, we evaluated the feasibility of [18F]FDG PET/MRI to detect metabolic and anatomic changes associated with CRPS. Radiologic evaluation and quantitative comparison confirmed that all seven patients with lower extremity CRPS exhibited significantly increased metabolism on [18F]FDG PET, possibly from inflammatory processes in CRPS. Though the statistical significance was shown $(p<0.05)$, the absolute difference between [18F]FDG uptakes of controls and patients was relatively small compared to the differences commonly reported from the study of other diseases, such as cancer. This may suggest that a different standard should be applied to examine the [18F]FDG PET images of CRPS. Also, no single common abnormality was found in the affected limbs across all patients, reflecting the complicated heterogeneity of CRPS pathology.

Gross morphologic changes or signal abnormalities were identified at the site of elevated [18F]FDG uptake on MRI, but only from three patients (Patients 5,6, and 7). This suggests metabolic interrogation with [18F]FDG PET may identify CRPS-induced changes earlier than MRI, and therefore potentially promote early and effective management of CRPS [11]. Note that the tissue classification of lesions with high [18F]FDG uptake was only enabled by structural MRI data. For example, the subcutaneous tissue uptake in Figure 4 would probably have been misclassified into the muscle uptake if judged only by its location on PET images.

Our imaging findings may facilitate specific subtyping or staging of CRPS. All abnormal PET uptake was locally confined except the case of Patient 3 presenting the global uptake on multiple neurovascular bundles (Figure 3B). This likely supports the reported heterogeneity in the disease mechanism of CRPS [12], which could impart differing management approaches. High [18F]FDG uptake on the edematous skin and subcutaneous tissue (Figure 4) is another feature that could be unique to a specific subtype or stage of CRPS. Hypermetabolic edema as shown in Figure 4 may also indicate a possibility to identify an inflammatory subtype of CRPS because edema is supposedly composed of body fluid, lacking the cellular components for increased metabolism. However, this may need further validation because the elevated uptake of [18F]FDG can be also related to extravasated blood pool or increased volume of inflammation/infection. It should be also noted that three cases of CRPS type I showed abnormal [18F]FDG uptake on peripheral nerves, while the only case of CRPS type II presented both PET and MRI abnormalities at the suspected nerve. This suggests that our method may provide the increased sensitivity to the causative nerve damage for the improved distinction between CRPS type I and II. 
Our study has a few limitations. Firstly, the number of enrolled patients and healthy controls was insufficient to group our heterogenous findings and associate them with specific aspects of CRPS. Our validation of the detected abnormalities regarding their potential contribution to pain is supported by their location, radiologic review and statistical comparison. However, a more direct evaluation of their association with pain, such as the outcome assessment of local anesthetic injection to detected abnormalities, would be desirable. Rescanning of the patient after treatments to associate the change of the abnormal uptake with the pain assessment could be another option. There may be a chance that factors other than inflammation, such as increased muscle recruitment from limping, could result in increased muscular uptake of [18F]FDG in the favored limb. Therefore, additional diagnostic information, potentially through developments of novel MRI techniques in our case, might be necessary to improve the specificity.

In conclusion, we present a novel [18F]FDG PET/MRI approach that identified metabolic and structural abnormalities in muscles, neurovascular bundles, and skin likely due to the inflammatory process of CRPS. Our preliminary results demonstrate the diagnostic potential of this approach for the non-invasive monitoring of distribution and progression of CRPS-induced changes.

\section{Abbreviations}

CRPS: Complex regional pain syndrome

MRI: Magnetic resonance imaging

PET: Positron emission tomography

[18F]FDG: [18F]fluorodeoxyglucose

SUV max $_{\text {: }}$ maximum standardized uptake value

\section{Declarations}

\section{Ethics approval and consent to participate.}

This study was approved by the institutional review board of Stanford university. All research data such as participant information and images were acquired in compliance with the Health Insurance Portability and Accountability Act. Informed consent was obtained from all individual participants included in the study.

\section{Consent for publication}

All individual participants signed informed consent regarding publishing their data and acquired images.

\section{Availability of data and material}


The datasets generated during and/or analyzed during the current study are not publicly available due to the fact we are 1) describing the off-label use of [18F]fluorodeoxyglucose and 2) the data is currently being utilized/analyzed for development of intellectual property, but are available from the corresponding author on reasonable request.

\section{Competing interests}

The authors, Daehyun Yoon, Peter Cipriano, and Sandip Biswal, received research support from General Electric Healthcare. No other potential conflicts of interest relevant to this article exist.

\section{Funding}

This study was in funded by NIH P41 EB015891 and General Electric Healthcare.

\section{Authors' contributions}

Conceptualization: Vivianne L. Tawfik, Catherine M. Curtin, lan R. Carroll, Sandip Biswal; Methodology: Daehyun Yoon, Yingding Xu, Carina A. Mari Aparici, Peter W. Cipriano, Israt S. Alam; Formal analysis and investigation: Daehyun Yoon, Yingding Xu, Peter W. Cipriano, Sandip Biswal; Writing - original draft preparation: Daehyun Yoon, Writing - review and editing: all authors; Funding acquisition: Sandip Biswal; Resources: Peter W. Cipriano, Carina A. Mari Aparici, Sandip Biswal; Supervision: Sandip Biswal.

\section{Acknowledgements}

This study was supported by NIH P41 EB015891 and General Electric Healthcare.

\section{Reference}

1. Janig W, Baron R. Complex regional pain syndrome: mystery explained? Lancet Neurol. 2003;2:68797. doi:10.1016/s1474-4422(03)00557-x.

2. Birklein F, Handwerker HO. Complex regional pain syndrome: how to resolve the complexity? Pain. 2001;94:1-6. doi:10.1016/s0304-3959(01)00393-1.

3. Schurmann M, Zaspel J, Lohr P, Wizgall I, Tutic M, Manthey N, et al. Imaging in early posttraumatic complex regional pain syndrome: a comparison of diagnostic methods. Clin J Pain. 2007;23:449-57. doi:10.1097/AJP.0b013e31805c9e66.

4. Lee GW, Weeks $P M$. The role of bone scintigraphy in diagnosing reflex sympathetic dystrophy. $J$ Hand Surg Am. 1995;20:458-63. doi:10.1016/S0363-5023(05)80107-8.

5. Graif M, Schweitzer ME, Marks B, Matteucci T, Mandel S. Synovial effusion in reflex sympathetic dystrophy: an additional sign for diagnosis and staging. Skeletal Radiol. 1998;27:262-5. doi: $10.1007 / \mathrm{s} 002560050378$.

6. Iolascon G, de Sire A, Moretti A, Gimigliano F. Complex regional pain syndrome (CRPS) type I: historical perspective and critical issues. Clin Cases Miner Bone Metab. 2015;12:4-10. 
doi:10.11138/ccmbm/2015.12.3s.004.

7. Cipriano PW, Yoon D, Gandhi H, Holley D, Thakur D, Hargreaves BA, et al. (18)F-FDG PET/MRI in Chronic Sciatica: Early Results Revealing Spinal and Nonspinal Abnormalities. J Nucl Med. 2018;59:967-72. doi:10.2967/jnumed.117.198259.

8. Harden RN, Bruehl S, Perez RS, Birklein F, Marinus J, Maihofner C, et al. Validation of proposed diagnostic criteria (the "Budapest Criteria") for Complex Regional Pain Syndrome. Pain. 2010;150:268-74. doi:10.1016/j.pain.2010.04.030.

9. Sekine T, Buck A, Delso G, Ter Voert EE, Huellner M, Veit-Haibach P, et al. Evaluation of Atlas-Based Attenuation Correction for Integrated PET/MR in Human Brain: Application of a Head Atlas and Comparison to True CT-Based Attenuation Correction. J Nucl Med. 2016;57:215-20. doi:10.2967/jnumed.115.159228.

10. Wollenweber SD, Ambwani S, Lonn AHR, Shanbhag DD, Thiruvenkadam S, Kaushik S, et al. Comparison of 4-class and continuous fat/water methods for whole-body, MR-based PET attenuation correction. IEEE Trans Nucl Sci. 2013;60:3391-0.

11. Kingery WS. A critical review of controlled clinical trials for peripheral neuropathic pain and complex regional pain syndromes. Pain. 1997;73:123-39. doi:10.1016/s0304-3959(97)00049-3.

12. David Clark J, Tawfik VL, Tajerian M, Kingery WS. Autoinflammatory and autoimmune contributions to complex regional pain syndrome. Mol Pain. 2018;14:1744806918799127. doi:10.1177/1744806918799127.

\section{Tables}

Table 1. Initial evaluation results of the recruited CRPS patients

\begin{tabular}{|c|c|c|c|}
\hline Patient number & Pain location & Duration & CRPS Type \\
\hline 1 & Right foot/leg & 7 years & 1 \\
\hline 2 & Left foot/ankle & 5 years & 1 \\
\hline 3 & Bilateral foot/leg & 5 years & 1 \\
\hline 4 & Right foot & 4 years & I \\
\hline 5 & Right foot/leg & 2 years & I \\
\hline 6 & Left foot/leg & 2 years & II \\
\hline 7 & Left foot & 7 years & I \\
\hline
\end{tabular}


Table 2. Identified [18F]FDG PET and MRI abnormalities of foot muscles, neurovascular bundles, and skin from 7 CRPS patient participants.

\begin{tabular}{|c|c|c|c|c|}
\hline $\begin{array}{l}\text { Patient } \\
\text { number }\end{array}$ & Modality & Muscle & Neurovascular bundle & Skin \\
\hline \multirow[t]{2}{*}{1} & PET & $\begin{array}{l}\text { High FDG } \\
\text { uptake on right } \\
\text { dorsal foot } \\
\text { muscles }\end{array}$ & None & None \\
\hline & MRI & None & None & None \\
\hline \multirow[t]{2}{*}{2} & PET & $\begin{array}{l}\text { High FDG } \\
\text { uptake on left } \\
\text { plantar foot } \\
\text { muscles }\end{array}$ & None & None \\
\hline & MRI & None & None & None \\
\hline \multirow[t]{2}{*}{3} & PET & $\begin{array}{l}\text { High FDG } \\
\text { uptake on left } \\
\text { plantar foot } \\
\text { muscles }\end{array}$ & $\begin{array}{l}\text { High FDG uptake on } \\
\text { bilateral plantar, tibial, } \\
\text { femoral, popliteal nerves }\end{array}$ & None \\
\hline & MRI & None & None & None \\
\hline \multirow[t]{2}{*}{4} & PET & $\begin{array}{l}\text { High FDG } \\
\text { uptake on right } \\
\text { ankle scar, } \\
\text { muscles }\end{array}$ & $\begin{array}{l}\text { High FDG uptake on } \\
\text { right posterior tibial } \\
\text { nerve }\end{array}$ & None \\
\hline & MRI & None & None & None \\
\hline \multirow[t]{2}{*}{5} & PET & None & None & $\begin{array}{l}\text { High FDG uptake on } \\
\text { subcutaneous / skin tissue } \\
\text { from the right distal thigh to } \\
\text { the foot }\end{array}$ \\
\hline & MRI & None & None & $\begin{array}{l}\text { Skin thickening and } \\
\text { subcutaneous edema } \\
\text { throughout the right leg }\end{array}$ \\
\hline \multirow[t]{2}{*}{6} & PET & None & $\begin{array}{l}\text { High FDG uptake on left } \\
\text { saphenous nerve }\end{array}$ & $\begin{array}{l}\text { High FDG uptake on } \\
\text { subcutaneous tissue around } \\
\text { left medial and lateral malleoli }\end{array}$ \\
\hline & MRI & None & $\begin{array}{l}\text { Enlarged left saphenous } \\
\text { nerve }\end{array}$ & $\begin{array}{l}\text { Subcutaneous tissue } \\
\text { thickening around left medial } \\
\text { and lateral malleoli }\end{array}$ \\
\hline \multirow[t]{2}{*}{7} & PET & $\begin{array}{l}\text { High FDG } \\
\text { uptake on left } \\
\text { dorsal foot } \\
\text { muscles }\end{array}$ & $\begin{array}{l}\text { High FDG uptake on the } \\
\text { left saphenous nerve }\end{array}$ & None \\
\hline & MRI & None & $\begin{array}{l}\text { Increased signal on the } \\
\text { left saphenous, sural } \\
\text { nerves }\end{array}$ & None \\
\hline
\end{tabular}




\section{Figures}

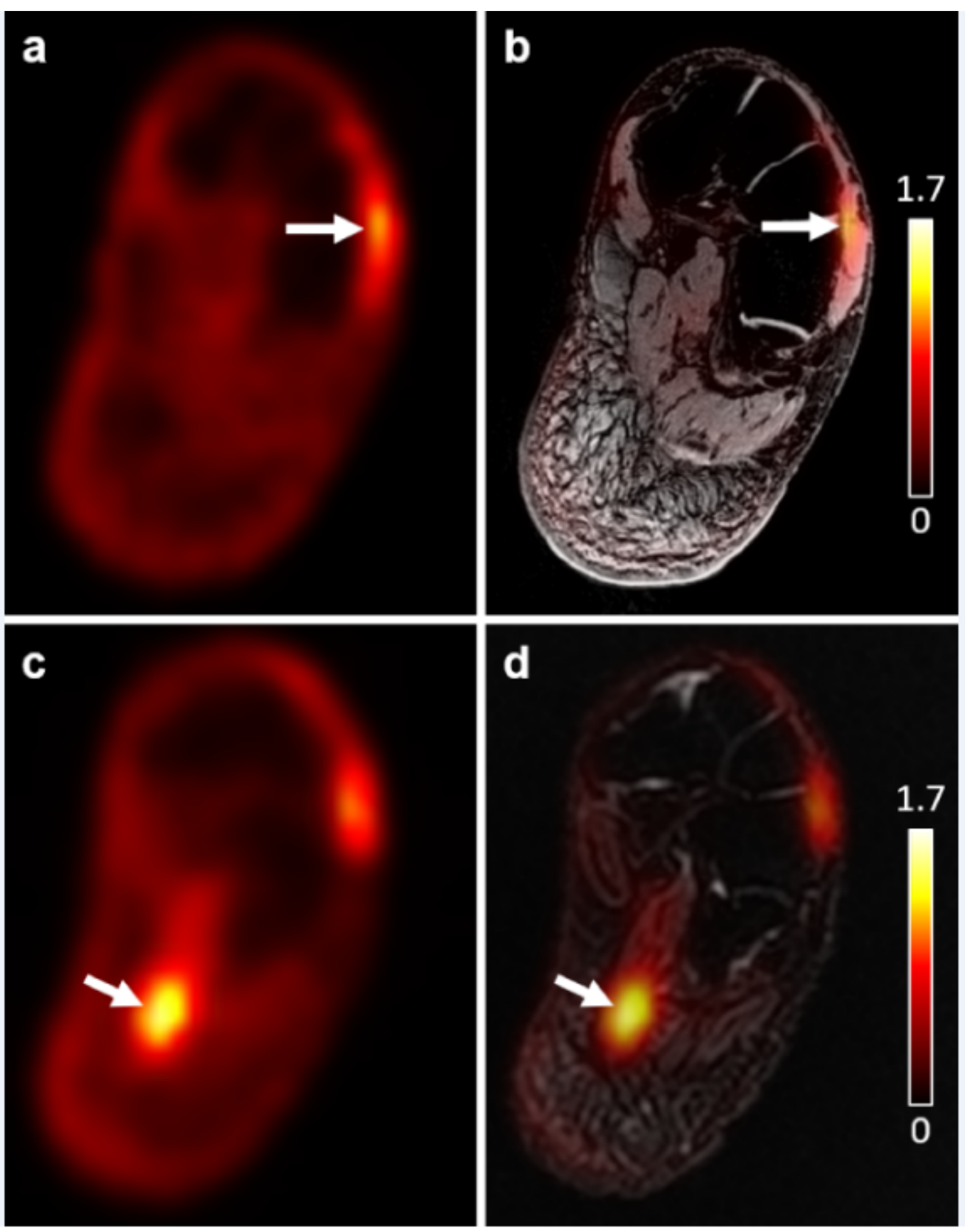

\section{Figure 1}

Locally high [18F]FDG uptake on foot muscles at the site of pain symptom. High [18F]FDG uptake was identified (red arrows) on the left extensor digitorum brevis muscle (A: PET only, B: PET/MRI coregistered) from patient 7 and left flexor digitorum brevis muscle (C: PET only, D: PET/MRI co-registered) 
from patient 2. No structural damage or abnormal signal intensity was observed on the MRI image. The unit of PET signal on the images is SUV. The same color scale (0-1.7) was used for all subfigures for PET.

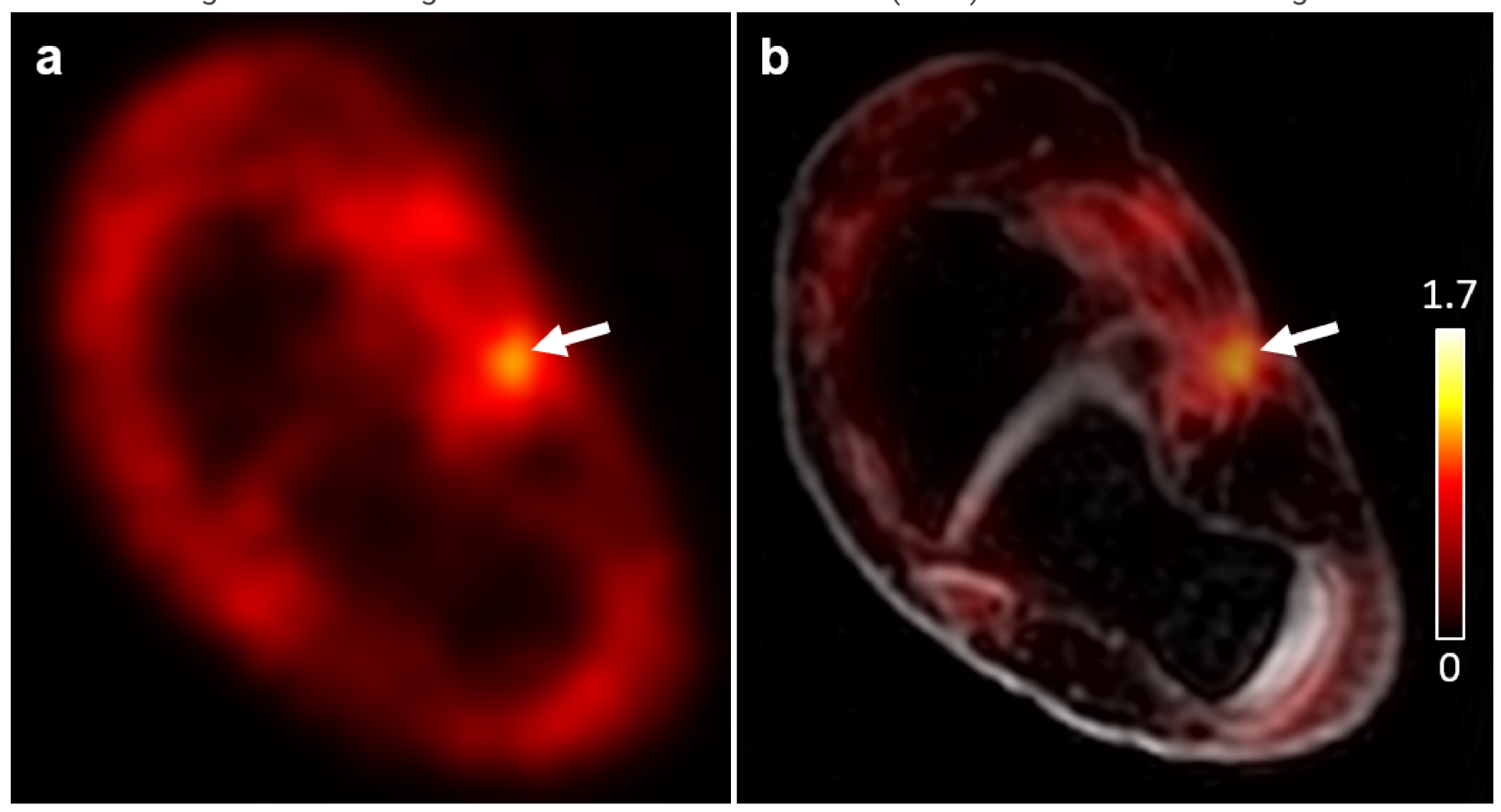

\section{Figure 2}

Increased [18F]FDG uptake on neurovascular bundles at the site of pain symptom. Locally increased [18F]FDG uptake was detected on the tibial neurovascular bundle passing through the scar tissue at the ankle of patient 4 and marked by the yellow arrow (A: PET only, B: PET/MRI co-registered). The unit of PET signal on the images is SUV. The same color scale (0-1.7) was used for all subfigures for PET. 


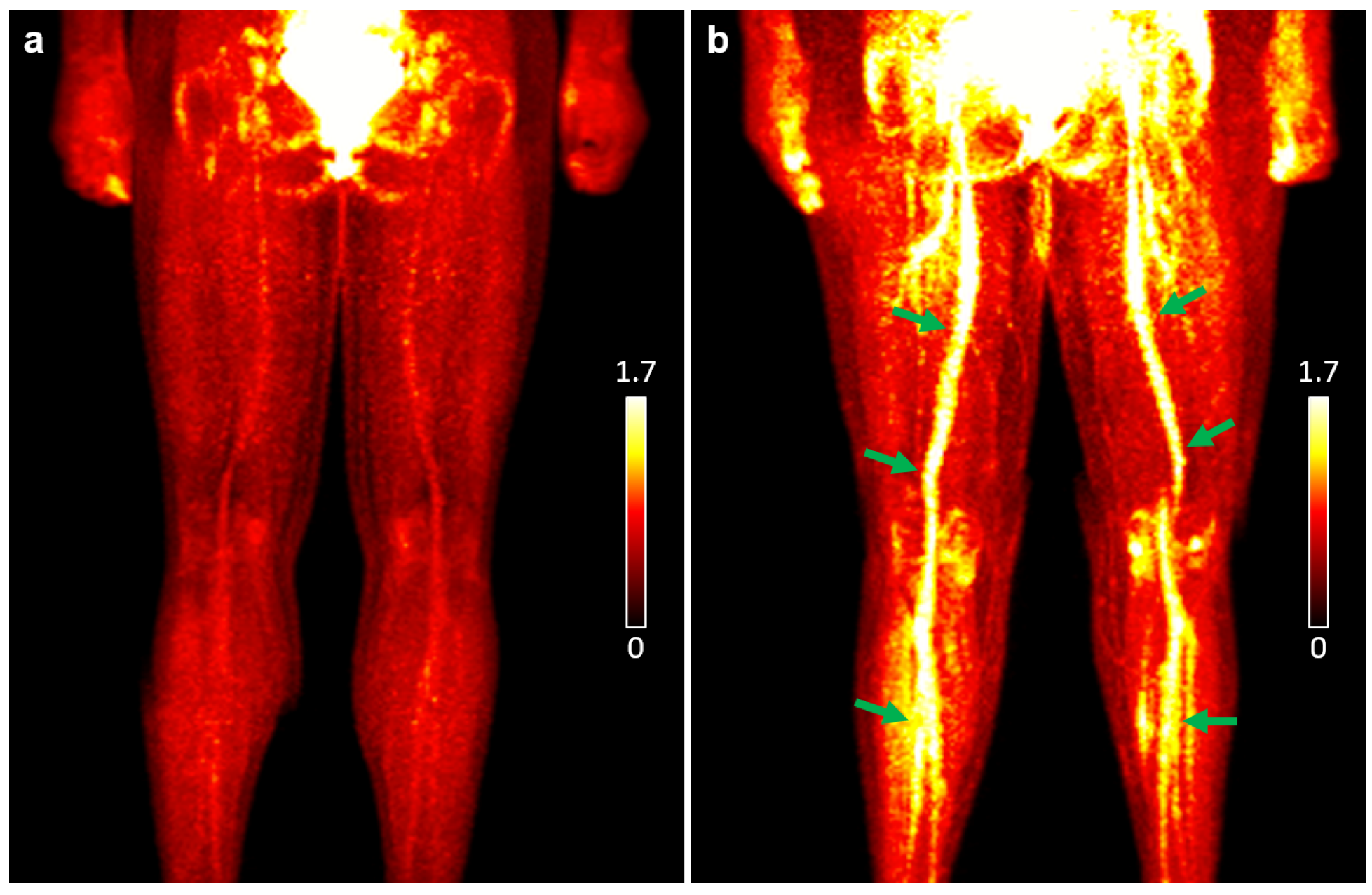

\section{Figure 3}

Globally Increased [18F]FDG uptake on neurovascular bundles along the site of pain symptom on maximum intensity projection PET images. Healthy controls did not present noticeably high [18F]FDG uptake on neurovascular bundles compared to the background tissues as shown in a representative control (A: PET only). However, a significantly increased [18F]FDG uptake was found bilaterally on multiple neurovascular bundles from patient 3 with bilateral foot and leg pain (B: PET only, white arrows). The unit of PET signal on the images is SUV. The same color scale (0-1.7) was used for all subfigures.

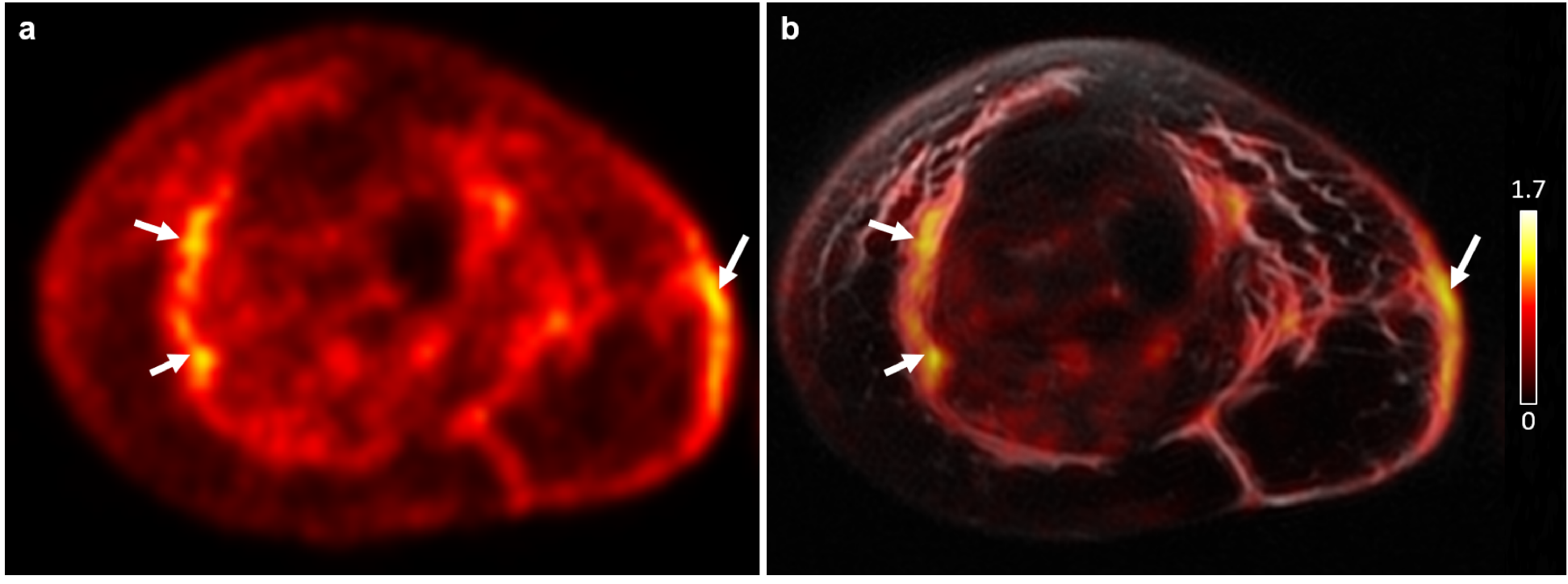


Figure 4

[18F]FDG PET and MRI abnormalities of skin and subcutaneous tissue of the symptomatic lower leg from patient 5 (A: PET only, B: PET/MRI co-registered). Increased uptake of [18F]FDG was identified on PET (white arrows) where edematous skin and subcutaneous tissue thickening was detected on MRI. The unit of PET signal on the images is SUV. The same color scale (0-1.7) was used for all subfigures for PET.

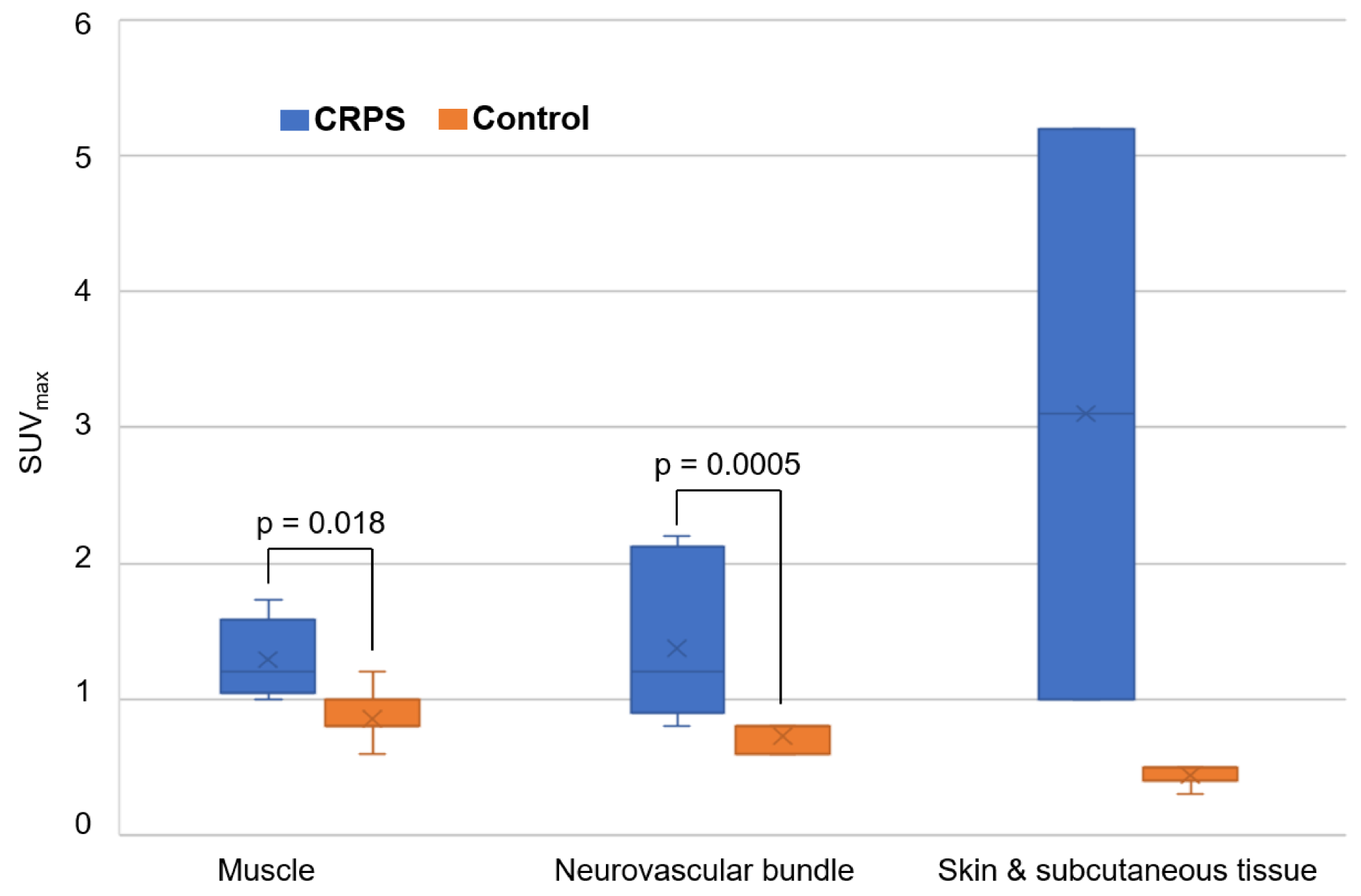

\section{Figure 5}

Mean and standard deviation of [18F]FDG SUVmax in muscle, neurovascular bundle, and skin lesions of CRPS patients and corresponding tissues of healthy controls. SUVmax in the lesions in muscle and nerve tissues show statistically significant difference than controls $(p<0.05)$. 